\title{
Pengaruh Media Kartu Cerita terhadap Kemampuan Menentukan Ide Pokok Paragraf Siswa Kelas V SD Inpres 5 Doom
}

\author{
Yofita M. Seso $^{1}$, Solehun $^{2} \&$ Teguh Yuliandri Putra ${ }^{3}$
}

Prodi PGSD, Universitas Pendidikan Muhammadiyah Sorong, Indonesia

${ }^{凶}$ E-mail: Alfianjoker@gmail.com

\begin{abstract}
Abstrak
Penelitian yang dilakukan berdasarkan hasil pretest dan postest yang peneliti temukan di SD Inpres 5 Doom, yaitu Media Kartu Cerita Terhadap Kemampuan Menentukan Ide Pokok Paragraf Siswa Kelas V SD Inpres 5 Doom merupakan media yang membantu siswa untuk memahami ide pokok paragraf dengan mudah. Tujuan dari penelitian ini untuk mengatahui pengaruh media kartu cerita terhadap kemampuan menentukan ide pokok paragraf. Penelitian ini menggunakan metode kuantitatif dengan desain penelitian eksperimen. Subjek penelitian ini adalah siswa kelas V SD Inpres 5 Doom yang berjumlah 20 siswa. Penelitian ini menggunakan teknik tes dan dokumentasi. Hasil dari penelitian yang dilakukan bahwa besarnya pengaruh media kartu cerita dapat dilihat dari hasil perhitungan uji-t pada hasil post test berdasarkan perhitungan maka diperoleh thitung sebesar 3.712 dengan Df $=20$ diperoleh ttabel sebesar 1.717, dengan taraf signifikansinya 0.05 , yakni $(0,00<0,05$ maka hipotesis diterima, berarti dapat disimpulkan bahwa terdapat pengaruh media kartu cerita terhadap kemampuan menentukan ide pokok paragraf siswa kelas 5 SD Inpres 5 Doom.
\end{abstract}

Kata Kunci: Media Kartu Cerita; Kemampuan Ide Pokok Paragrap; Siswa Kelas V

\begin{abstract}
The research was conducted based on the results of the pretest and posttest that the researchers found at SD Inpres 5 Doom, namely Story Card Media Against the Ability to Determine Main Paragraph Ideas for Class V Students of SD Inpres 5 Doom is a medium that helps students to understand the main ideas of paragraphs easily. The purpose of this study was to determine the effect of story card media on the ability to determine paragraph main ideas. This research uses quantitative methods with experimental research design. The subjects of this study were 20 grade students of SD Inpres 5 Doom, totaling 20 students. This research uses test and documentation techniques. The results of the research carried out that the magnitude of the influence of the story card media can be seen from the results of the $t$-test calculation on the results of the post-test based on the calculation, so that the t-count is 3,712 with $D f=20$, the t table is 1.717, with a significance level of 0.05 , namely $(0.00<0.05$, the hypothesis is accepted, it means that it can be concluded that there is an effect of story card media on the ability to determine the main idea paragraphs of grade 5 students of SD Inpres 5 Doom.
\end{abstract}

Keywords: Story Cards Media; Paragraph Main Idea Ability; Class V Student 


\section{PENDAHULUAN}

Pendidikan merupakan suatu usaha sadar yang dimiliki manusia untuk menumbuh kembangkan ilmu pengetahuan. Di dalam dunia pendidikan terdapat beberapa mata pelajaran yang di keluarkan oleh kurikulum dalam meningkatkan ilmu pengetahuan siswa salah satunya adalah mata pelajaran bahasa indonesia.

Pembelajaran bahasa indonesia adalah pelajaran yang mengembankan pengetahuan, pemahaman, saling berinteraksi dan menumbuhkan rasa persatuan terhadap bangsa Indonesia. Pembelajaran bahasa indonesia menurut (Khair, U.2018). disuguhkan pada peserta didik bertujuan untuk melatih peserta didik terampil berbahasa dengan menuangkan ide dan gagasanya secara kreatif dan kritis. Namun kenyataannya banyak guru terjebak dalam tatanan konsep sehingga pembelajaran cenderung membahas teori-teori bahasa. Sebagaimana yang dikemukakan Slamet dalam (Khair, U. 2018) bahwa pengajaran bahasa Indonesia adalah pengajaran keterampilan berbahasa bukan pengajaran tentang kebahasaan. Teori-teori bahasa hanya sebagai pendukung atau penjelas dalam konteks, yaitu yang berkaitan dengan keterampilan tertentu misalnya dalam hal membaca.

Pada era perkembangan ilmu pengetahuan dan teknologi yang berkembang pesat seperti sekarang ini di rasakan bagi kehidupan manusia tidak bisa lepas dari kegiatan membaca. Imformasi yang setiap hari diterima manusia memberi sebagian besar semuanya itu disampaikan melalui media cetak elektronik yang melalui lisan ataupun tulisan. Untuk itu dibutuhkan keterampilan membaca dalam memahaminya. Kegiatan membaca menjadi kebutuhan hidup manusia sehari-hari seperti halnya makan dan minum. Kemampuan untuk membaca seseorang dapat diperoleh maupun dilatih melalui dunia pendidikan. Membaca merupakan kegiatan produktif seseorang untuk mengetahui maksud maupun tujuan dari penulis. Dalam membaca siswa di tuntut untuk aktif daam menggali imformasi yang di baca. Tahapan membaca bagi seorang siswa sangat penting karena hal itu akan sangat berpengaruh pada sikap dan imformasi yang didapatkan dalam suatu bacaan sehingga apa yang telah dibacakanya dapat dipahami dengan baik.

Hal ini tidak sejalan dengan penitian yang lakukan pada saat magang 3 yang diteliti d SD Inpres 5 Doom, kemampuan siswa dalam hal menentukan ide pokok paragraf di kelas 5 SD Inpres 5 Doom, tidak sesuai dengan harapan. Banyak siswa belum mampu dalam menentukan ide pokok paragraf hal ini disebabkan oleh latihan kemampuan menentukan ide pokok paragraf cendrung pada pemahaman (literal) tingkat rendah, dan cendrung kegiatan individual tingkat rendah dan cendrung kegiatan individual, proses pembelajaran membaca pada umumnya adalah interaksi searah yaitu membaca teks dan selanjutnya menjawab pertanyaan dibawah teks dibawah teks secara individu, disisi lain guru juga tidak menggunakan strategi membaca yang menarik bagi siswa dalam pembelajaran membaca pemahaman di kelas V SD Inpres 5 Doom.

Berdasarkan permasalahan tersebut untuk mengatasinya peneliti memiliki alternatif pada siswa sekolah SD Inpres 5 Doom kelas V kususnya pada pelajaran bahasa indonesia dengan materi ide pokok paragraf peneliti tertarik menggunakan media pembelajaran kartu cerita untuk mengetahui hasil belajar pada materi ide pokok paragraf.

Media adalah salah satu sarana yang 
dapat membantu dan memudahkan guru untuk mentransfer materi kepada siswa. Media sangat penting digunakan dengan adanya bantuan media siswa dapat mudah memahami materi yang diberikan oleh guru. Menurut Asra (dalam Lina,dkk 2014) kata media dalam "media pembelajaran" secara harfiah berarti perantara atau pengantar ; sedangkan kata pembelajaran diartikan sebagai suatu kondisi yang diciptakan untuk membuat seseoran melakukan suatu kegiatan belajar. Dengan demikian media pembelajran menekankan pada posisi media sebagai wahana penyalur pesan atau imformasi belajar untuk mengkodisikan seseorang untuk belajar. Dengan kata lain, pada saat kegiatan belajar berlangsung bahan belajar yang diterima oleh siswa diperoleh dari media.

Salah satu media yang digunakan adalah kartu cerita. Media kartu cerita salah satu alat pembelajaran yang berisi kalimat digunakan dalam upaya meningkatkan kemampuan mutu ilmu pengetahuan dalam materi ide pokok paragraf. Dengan bantuan media kartu cerita siswa dapat lebih mudah memahami cara untuk menemukan ide pokok paragraf dengan baik. Menurut (Fanny ;2013) media pembelajaran merupakan sarana agar peserta didik tidak jenuh dalam mengikuti pelajaran dan efek yang terbesar diharapkan peserta didik dapat termotivasi dan mempermudah dalam menerima materi pelajaran. Sedangkan Menurut Latuheru, dalam Arsyad (2014:4) mengatakan bahwa media adalah semua bentuk perantara yang digunakan oleh manusia untuk menyampaikan atau menyebarkan ide, gagasan, atau pendapat sehingga ide , gagasan.

Burns (dalam rahim, 2011:99) mengemukakan bahwa pengajaran membaca di landasi oleh pandangan teori skemata.
Tarigan (2009:3) mengatakan bahwa ide pokok suatu wacana perlu mendapat perhatian secara tersendiri karena berhubungan erat dengan tema, persoalan persoalan yang terkandung dalam suatu wacana.

Pengertian media kartu cerita yang digagas oleh Kemendikbud (dalam Mayawati, dkk 2014) media pembelajaran kartu cerita merupakan sebuah kartu yang berisi kalimat utama yang harus dikembangkan sendiri oleh peserta didik agar menjadi sebuah karangan yang utuh. Tujuan dari penelitian ini Untuk mengetahui pengaruh media kartu cerita terhadap kemampuan menentukan ide pokok paragraf siswa kelas V SD Inpres 5 Doom.

\section{METODE PENELITIAN}

Penelitian ini termasuk jenis penelitian kuantitatif dengan metode eksperimen. Penelitian ini dilaksanakan di SD Inpres 5 Doom, Kelurahan Doom Timur Distrik Sorong Kepulauan Kota Sorong. populasi dalam penelitian ini adalah seluruh siswa kelas V SD Inpres 5 Doom yang berjumlah 30 siswa. Dalam penelitian ini sampel yang akan diambil adalah siswa kelas V SD Inpres 5 Doom yang berjumlah 20 siswa yang terdiri dari 14 siswa laki-laki dan 6 siswa perempuan. Instrument dalam penelitian ini berupa tes dan dokumentasi.

\section{HASIL DAN PEMBAHASAN}

Penelitian ini menggunakan intrumen penelitian berupa tes yaitu pre test berjumlah 10 item pernyataan media kartu cerita serta post test berjumlah 20 item kemampuan menentukan ide pokok paragraf. Sebelum soal diberikan kepada siswa di sekolah, terlebih dahulu dikonsultasikan dengan satu professional Judgment dosen PGSD Unimuda Sorong dengan cara dimintai 
pendapat tentang instrument yang telah disusun oleh peneliti. Ahli tersebut menyatakan bahwa instrument angket yang telah dibuat tersebut telah layak digunakan dengan catatan revisi.

Uji Reliabilitas digunakan untuk mengetahui apakah butir soal pre test yang diujikan reliabel dalam memberikan pengukuran terhadap siswa. Untuk menguji reliabilitas instrumen peneliti menggunakan SPSS V24.0 dengan hasil uji relibilitas sebagai berikut.

Berdasarkan perhitungan uji reliabilitas terhadap instrument pre test dan posttest menggunakan SPSS V24.0 diperoleh hasil cronbach's Alpha untuk instrumen pre test sebesar 0,610 dan posttest sebesar 0,780. Dengan demikian, kedua instrument tes tersebut dinyatakan telah memenuhi syarat reliabel.

Tabel 1. Hasil Belajar Awal dan Akhir (pretest dan post test)

\begin{tabular}{clcc} 
No. & Nama Siswa & \multicolumn{2}{c}{ Hasil } \\
& & Pre Test & Post Test \\
\hline 1. & Abm & 40 & 70 \\
2. & Afw & 60 & 90 \\
3. & Amm & 40 & 70 \\
4. & Bsa & 60 & 75 \\
5. & Frb & 30 & 70 \\
6. & Idm & 70 & 90 \\
7. & Mdr & 40 & 80 \\
8. & Fmp & 30 & 80 \\
9. & Mtm & 70 & 70 \\
10. & Mfm & 40 & 80 \\
11. & Mya & 40 & 85 \\
12. & Rr & 60 & 75 \\
13. & Rds & 20 & 80 \\
14. & Rzy & 30 & 85 \\
15. & Sbm & 30 & 80 \\
16. & Smm & 50 & 75 \\
17. & Ven & 40 & 80 \\
18. & Wfm & 20 & 80 \\
19. & Wih & 60 & 90 \\
20. & Zm & 50 & 70
\end{tabular}

Dari data tabel 1 di atas menunjukan hasil pretest diketahui dari 20 siswa, 2 siswa memiliki nilai terendah 20, 4 siswa memiliki nilai sedang 30 dan 2 siswa memiliki nilai tinggi 70. Dapat disimpulkan hasil pre test data siswa dari 20 respoden rata-rata nilai tes yang dicapai siswa dibawah rata-rata sebelum diberikan perlakuan oleh peneliti.

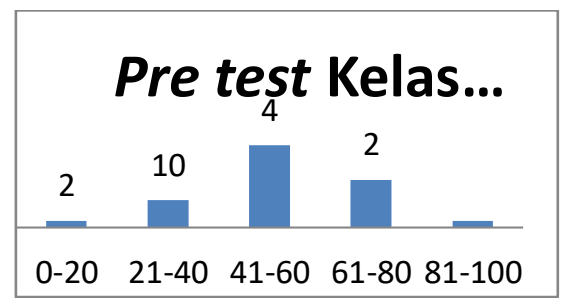

Gambar 1. Grafik frekuensi pre test kelas eksperimen

Berdasarkan gambar 1 distribusi frekuensi hasil pretest siswa kelas eksperimen yang berjumlah 20 orang siswa dapat diinterpretasikan sebanyak 10 siswa yang memperoleh data dibawah interval ratarata. Sedangkan siswa yang memiliki nilai diatas interval rata-rata adalah 2 orang siswa.

Sedangkan hasil post tesnya di ketahui dari 20 siswa, 5 siswa memiliki nilai terendah 70, 1 siswa memiliki nilai sedang 85 dan 4 siswa memiliki nilai tinggi 90. Dapat disimpulkan hasil post test data siswa dari 20 respoden rata-rata nilai tes yang dicapai siswa diatas rata-rata setelah diberikan perlakuan oleh peneliti.

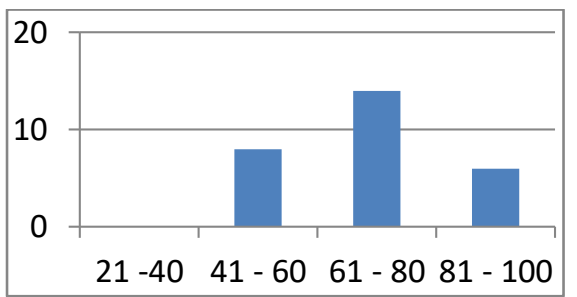

Gambar 2 Grafik frekuensi post test kelas eksperimen

Berdasarkan gambar 2 distribusi frekuensi hasil post test siswa kelas eksperimen yang berjumlah 20 orang siswa dapat diinterpretasikan sebanyak 5 siswa yang memperoleh data dibawah interval ratarata. Sedangkan siswa yang memiliki nilai diatas interval rata-rata adalah 15 siswa. 
Tabel 2. Uji T-tes

One-Sample Kolmogorov-Smirnov Test

Unstandardized

Residual

\begin{tabular}{l|ll}
\hline $\mathrm{N}$ & \multicolumn{2}{l}{20} \\
\hline Normal & Mean &, 0000000 \\
\cline { 2 - 3 } Parameters & Std. & 5,01405267 \\
& Deviation \\
\hline Most Extreme & Absolute &, 102 \\
\cline { 2 - 3 } Differences & Positive &, 102 \\
\cline { 2 - 3 } & Negative &,- 085 \\
\hline Kolmogorov-Smirnov Z &, 870 \\
\hline Asymp. Sig. (2-tailed) &, $200^{\mathrm{c}, \mathrm{d}}$ \\
\hline
\end{tabular}

Berdasarkan data dari tabel 2 di atas, di peroleh hasil bahwa nilai kolmogorovsmirnov sebesar 0,870 dengan sig sebesar 0,200. Dari data tersebut dapat dilihat bahwa Asymp Sig (2-tailed) distribusi data yang diperoleh lebih besar dari 0,05. Dapat disimpulkan bahwa Asymp Sig (2-tailed) distribusi data media kartu cerita terhadap kemampuan menentukan ide pokok paragraf siswa kelas V Sd Inpres 5 Doom pada masing-masing variabel normal sehingga dapat digunakan untuk uji t.

Tabel 3 Uji One Sample T- test

\begin{tabular}{lll}
\hline T & Df & Sig. (2 tailed) \\
\hline
\end{tabular}

Posttest $3.712 \quad 20$ 0,00

Pada pengujian hipotesis pada tabel 3 dengan menggunakan uji t- test one sample ttest karena hanya satu varian dimana data yang diuji yaitu hasil post test berdasarkan hasil perhitungan maka diperoleh thitung sebesar 3.712 dengan $\mathrm{Df}=20$ diperoleh ttabel sebesar 1.717, dengan taraf signifikansinya 0.05 , yakni $(0,00<0,05$ maka hipotesis diterima, berarti dapat disiimpulkan bahwa terdapat pengaruh media kartu cerita terhadap kemampuan menentukan ide pokok paragraf siswa kelas 5 SD Inpres 5 Doom. Sebelum penelitian dilakukan, terlebih dahulu peneliti menguji validitas instrumen yang akan digunakan sebagai instrumen penelitian untuk menentukkan bahwa instrumen tersebut layak diberikan kepada responden. Respoden yang diteliti yaitu siswa kelas 5 SD Inpres 5 Doom yang terdiri dari 20 siswa. Kemampuan menentukan ide pokok paragraf tersebut dapat diukur setelah diberikan perlakuan pada penggunaan media cerita menggunakan tes yang diberikan peneliti kepada responden. Siswa diberikan instrumen berbentuk tes pada isi pre test dan post test kemampuan menentukan ide pokok paragraf yang berisi 10 item pertanyaan pre test dan 20 pertanyaan post test media kartu cerita. Sebelum instrumen tersebut diberikan, terlebih dahulu dikonsultasikan dengan 1 Profesional Judgement sebagai dosen PGSD dalam bidang ahli bahasa dan media, yaitu dosen tetap Unimuda Sorong dengan cara divalidasi instrumen yang telah disusun oleh peneliti antara lain lembar test pre test dan post test. Ahli tersebut menyatakan bahwa instrumen yang telah dibuat telah layak dan dapat digunakan dengan sedikit revisi.

Setelah instrumen tersebut dinyatakan layak maka langkah selanjutnya yang dilakukan yaitu mencari reliabilitas instrumen tes, peneliti melakukan uji coba soal tes pre test dan post test pada siswa kelas 5. Berdasarkan perhitungan uji reliabilitas terhadap instrument tes menggunakan rumus alpha crobach, diperoleh hasil nilai reliabilitas untuk instrument tes pre test sebesar 0,610 sedangkan, tes post test sebesar 0,780 . Berdasarkan kriteria pengujian, jika nilai reliabilitas instrument tes $>0,05$ maka instrument pre test dan post test memenuhi syarat reliabel.

Penelitian mengolah data dengan melakukan uji prasyarat yaitu uji normalitas 
data. Berdasarkan pengolahan data uji normalitas diperoleh dari perhitungan dengan menggunakan SPPSV24 diketahui kemampuan menentukan ide pokok paragraf siswa kelas 5 memiliki taraf signifikansi $0,200>0,05$ sehingga dapat disimpulkan bahwa siswa kelas 5 sebagai lokasi penelitian kelas eksperimen berdistribusi normal. Dapat disimpulkan bahwa data dalam penelitian memiliki varian yang sama, dan data layak digunakan untuk uji selanjutnya, yaitu uji-t.

Pada pengujian hipotesis diatas dengan menggunakan uji t- test one sample test karena hanya terdapat satu varian dimana data yang diuji yaitu hasil post test dari kelas eksperimen berdasarkan perhitungan maka diperoleh thitung sebesar 3.712 dengan $\mathrm{Df}=$ 20 diperoleh ttabel $(3.712>1.717)$, dengan taraf signifikansinya 0.05 , yakni $(0,00<0,05$ maka hipotesis diterima, berarti dapat disiimpulkan bahwa terdapat pengaruh media kartu cerita terhadap kemampuan menentukan ide pokok paragraf siswa kelas 5 SD Inpres 5 Doom.

Hasil penelitian ini bisa dikatakan sama atau berhasil dilakukan oleh peneliti dengan didukung oleh penelitian terdahulu yaitu penelitian yang dilakukan oleh Penelitian yang dilakukan oleh (Nisa I. K 2019) dengan judul Pengembangan Media Flashcard Berbantuan Board Game Terhadap Hasil Belajar Menentukan Ide Pokok Paragraf Siswa Kelas Iva Sdn Petompon 02. Penelitian yang di lakukan oleh Rahma, U. L. (2019). Peningkatan Keterampilan Menyajikan Teks Persuasi Secara Tulis Melalui Model Scaffolding Dengan Media Kartu Cerita Lingkungan Kita (Kartalita) Pada Peserta Didik Kelas Viii A Smp Negeri 34 Semarang.

\section{KESIMPULAN}

Berdasarkan rumusan masalah dan hipotesis yang diajukan, serta hasil penelitian yang didasarkan pada analisis data dan pengujian hipotesis, maka kesimpulan yang dikemukan dalam penelitian ini yaitu terdapat pengaruh media kartu cerita terhadap kemampuan menentukan ide pokok paragraf siswa kelas 5 SD Inpres 5 Doom. Hal ini ditunjukan oleh nilai thitung $=3.712$, sedangkan ttabel pada taraf signifikansi $5 \%$ adalah 1.717. karena thitung > ttabel maka hipotesis diterima.

\section{DAFTAR RUJUKAN}

Arsyad Azhar. 2014. Media Pembelajaran. Jakarta : PT Raja Grafindo Perkasa

Fanny, Arif Mahya, Siti Partini Suardiman. 2013. Pengembangan Multimedia Interaktif untuk Mata Pelajaran Ilmu Pengetahuan Sosial (IPS) Sekolah Dasar Kelas V. Jurnal Prima Edukasia 1(1). https://journal.uny.ac.id/index.php/jpe/artic le/view/2311

Kuswanto, J., \& Radiansah, F. (2018). Media Pembelajaran Berbasis Android Pada Mata Pelajaran Sistem Operasi Jaringan Kelas XI. Jurnal Media Infotama, 14(1).

Khair, U. (2018). Pembelajaran Bahasa Indonesia dan Sastra (BASASTRA) di SD dan MI. AR-RIAYAH: Jurnal Pendidikan Dasar, 2(1), 81.

Nisa, I. K. (2019). Pengembangan Media Flashcard Berbantuan Board Game Terhadap Hasil Belajar Menentukan Ide Pokok Paragraf Siswa Kelas Iva Sdn Petompon 02 (Doctoral dissertation, Universitas Negeri Semarang).

Nurajijah, A. (2018). Menggunakan Media Kartu Cerita Untuk Menemukan Ide Pokok Paragraf Pada Pelajaran Bahasa Indonesia (Ptk Di Kelas Iv Sdit Nurul Hidayah Ciceri Serang-Banten) (Doctoral dissertation, Universitas Islam Negeri" Sultan Maulana Hasanuddin" Banten.

Rahmat, P. S., \& Heryani, T. (2014). Pengaruh Media Kartu Kata Terhadap Kemampuan Membaca dan 
Penguasaan Kosakata. Jurnal Pendidikan Usia Dini, 8(1), 101-110.

Rahma, U. L., \& Pristiwati, R. (2019). Keterampilan Menyajikan Teks Persuasi Melalui Model Scaffolding dengan Media Kartu Cerita Lingkungan Kita (Kartalita). Jurnal Profesi Keguruan, 5(2), 180183.

Rani, A. N. A. (2016). Hubungan Antara Penggunaan Media Kartu Gambar Cerita Berseri Dengan Kemampuan Berbicara Anak Usia Dini.

Samsu Somadayu. (2011). Strategi dan teknik pembelajaran membaca. Yogyakarta: Graha Ilmu.

Sudarwan Danim. (2014). Perkembangan
Peserta didik. Bandung: Penerbit Alfabeta.

Suci, A. M. (2019). Pengaruh Pembelajaran Stad (Student Achievement Divisions) Berbantuan Media Kartu Cerita Terhadap Keterampilan Menulis Cerita Pada Siswa (Penelitian dilakukan pada siswa kelas 3 di SD Negeri Sutopati 2) (Doctoral dissertation, Skripsi, Universitas Muhammadiyah Magelang).

Tafonao, T. (2018). Peranan media pembelajaran dalam meningkatkan minat belajar mahasiswa. Jurnal Komunikasi Pendidikan, 2(2), 103-114.

Tarigan, Henry Guntur. 2009 (Edisi Revisi). Pengajaran Wacana.Bandung : Angkasa 